\title{
Pruritus in pediatric patients with atopic dermatitis: a multidisciplinary approach - summary document from an Italian expert group
}

\author{
May El Hachem ${ }^{1 \dagger}$, Giuseppe Di Mauro ${ }^{2 \dagger}$, Roberta Rotunno ${ }^{1 *}$, Simona Giancristoforo ${ }^{1}$, Cristiana De Ranieri ${ }^{3}$, \\ Carla Maria Carlevaris ${ }^{4}$, Maria Carmen Verga ${ }^{5}$ and Iride Dello lacono ${ }^{6}$
}

\begin{abstract}
Given the inadequate overall awareness of the main disease features and treatment modalities of pruritus in pediatric patients with atopic dermatitis, a multidisciplinary Italian expert group met with the major aim of increasing knowledge of the condition for improved diagnosis and better management among specialists involved in disease management. Herein, the overall features of the condition are reviewed, along with its etiopathogenesis and symptoms. Likewise, management options are summarized, emphasizing the need for a multidisciplinary approach, minimally composed of a management team that includes a pediatrician, dermatologist, psychologist, play assistant, and dedicated nurse. In addition to more traditional therapies such as emollients as highlighted by European guidelines, therapeutic patient education in a group or individually is highly encouraged as it helps patients and their parents to better understand the disease and provide practical guidance for dressing and bandaging. It can also aid in outlining coping strategies for itching and sleep disturbance. The utility of distraction techniques should also be stressed as such educational interventions involving the child and their parents can substantially improve the overall quality of life. All approaches should be tailored according to patient age and clinical features and requires individualized strategy to ensure good adherence by both children and their parents. Thus, a holistic approach embracing systemic, topical and psychological interventions is advocated in order to provide patients and their caregivers the best possible care.
\end{abstract}

Keywords: Atopic dermatitis, Pruritus, Multidisciplinary approach, Therapeutic patient education

\section{Introduction}

Atopic dermatitis (AD) is a chronic multifactorial disorder that requires multidisciplinary management $[1,2]$. The recent literature confirms that the treatment of itching is a challenge. Unfortunately, opinions and approaches are discordant among physicians from the same or different specialties. This can cause confusion for patients and families with implications for decreased adherence to treatment and worsening of disease complications such

\footnotetext{
* Correspondence: roberta.rotunno@opbg.net

May El Hachem and Giuseppe Di Mauro co-author

${ }^{\dagger}$ May El Hachem and Giuseppe Di Mauro contributed equally to this work.

'Dermatology Unit, Bambino Gesù Children's Hospital, IRCCS, Piazza di

Sant'Onofrio, 4, 00165 Rome, Italy

Full list of author information is available at the end of the article
}

as lichenification, infection, and sleep disturbance, which negatively affects the overall quality of life (QoL). The therapeutic approach should be adapted to patient age and clinical features and requires a patient-tailored strategy to ensure good compliance by both children and their parents. Considering this aim, an Italian expert group has developed this document as a tool to different specialists involved in disease management (pediatrician, dermatologist, allergologist, psychologist, psychotherapist, play assistant, and nurses) to plan adequate and tailored treatment for each AD patient and itching. Herein, we provide a concise summary document that is relevant for practicing clinicians.

(c) The Author(s). 2020 Open Access This article is distributed under the terms of the Creative Commons Attribution 4.0 International License (http://creativecommons.org/licenses/by/4.0/), which permits unrestricted use, distribution, and reproduction in any medium, provided you give appropriate credit to the original author(s) and the source, provide a link to the Creative Commons license, and indicate if changes were made. The Creative Commons Public Domain Dedication waiver (http://creativecommons.org/publicdomain/zero/1.0/) applies to the data made available in this article, unless otherwise stated. 
Clinical features and differential diagnosis of $A D$

$\mathrm{AD}$ is most common during childhood [2]. The diagnosis of $\mathrm{AD}$ is generally easy and based on clinical features that vary upon patient age and disease severity (Table 1). In addition, other signs and symptoms may be associated and are helpful to confirm the diagnosis in some patients (Table 2). Differential diagnosis is always necessary and arises in a list of diseases from variable severity requiring different management approaches (Table 3).

\section{The etiopathogenesis of itching in AD}

Pruritus is the major and disrupting symptom of $\mathrm{AD}$ and is due to a complex interaction comprising skin barrier deficiency, immunological dysfunction, and central and peripheral neural mechanisms. Itching promotes a negative cycle described as "the itch that rashes" [2, 3]. Scratching causes further damage to the skin barrier, stimulating skin inflammation and inducing factors called pruritogens. (Fig. 1) This mechanism leads to the development, progression, chronicity of $\mathrm{AD}$, and complications [3, 4]. The main etiopathogenetic factors are summarized below as follows:

- Skin barrier disruption. AD is characterized by systematic epidermal barrier dysfunction; due to, at first, tight junction aberration with reduced expression of some claudins and zonulins. In addition, several mutations in the filaggrin gene have been identified. This filament is essential for controlling transepidermal water loss (TEWL) and maintaining stratum corneum organization and hydration [3-5]. Itch intensity in $\mathrm{AD}$ is associated with increased TEWL. Filaggrin deficiency also leads to an increase in cutaneous $\mathrm{pH}$, which enhances the function of kallikreins, or serine proteases known as pruritogens that are upregulated in $\mathrm{AD}[3,6]$. Moreover, epidermal barrier dysfunction allows for entry of irritants and pruritogens $[6,7]$.

- Immunological disorder. Skin barrier dysfunction and inflammation lead to an aberrant type 2 immune response, with increased IgE production, eosinophilia, mast cell activation, and overexpression of Th2 cytokines (IL-4, IL-5, IL-13). This cascade promotes production of epithelial-derived cytokines, namely, thymic stromal lymphopoietin (TSLP). TSLP influences innate lymphoid cells (ILCs) and increases the production of Th2 chemokines [4, 5, 8].

- Hyperinnervation of skin and central sensitization of itch. An increase in nerve fiber density in the epidermis reported in AD, which is partly explained by the increase in nerve growth factor observed in the plasma of $\mathrm{AD}$ patients. Moreover, some studies have implicated involvement of central nervous system structures and astrocytes in sensitization of itch. Other studies have revealed a central neural circuit that is critical for signal processing of itch $[9,10]$.

- Itch mediators/pruritogens. The sensation of itching is mediated by cytokines, neuropeptides, and endogenous secreted factors. These itch-inducing factors act on sensory neurons to drive itch sensation. Histamine is one of the earliest identified pruritogens; among four receptors, H1R and H4R are potential mediators of pruritus. Others endogenous and exogenous factors produced from inflammation and xerosis result in the induction of nonhistaminergic itch (i.e. protease astryptase, dust mites, Staphylococcus aureus, or substance P, TSLP, Notch proteins) $[5-7,11]$. Recently, a role of IL-31 produced by Th2 cells has been recognized in inducing itch $[12,13]$.

\section{Symptoms and complications Symptoms}

Pruritus can occur in different clinical forms depending on the age of the child, chronicity of symptoms, trigger factors, and psychological attitude. In AD, itching is the main, constantly present symptom, and is of variable intensity, associated with pain and/or burning, and generally worsens at night causing sleep disturbance.

Correct classification of symptoms and emotional consequences, due to a vicious circle, is essential to plan adequate management [14]. In the literature, there are 62 separate severity scales and 28 quality of life tools (QoL) used in clinical research; however, only 3 have been properly validated [15]. The most commonly used scales are the SCORAD index, the Eczema area and the

Table 1 Characteristic features of atopic dermatitis by age. Modified from Ref. [1]

\begin{tabular}{llll}
\hline AD & Infant & Childhood & Adolescent or Adult \\
\hline $\begin{array}{l}\text { Lesions } \\
\text { Exudative erythematous weepy papules } \\
\text { and plaques }\end{array}$ & $\begin{array}{l}\text { Weepy erythematous papules and plaques intermixed } \\
\text { with lichenified plaques, particularly in flexural areas }\end{array}$ & $\begin{array}{l}\text { Erythematous papules and } \\
\text { plaques with xerotic scale and } \\
\text { crust } \\
\text { Lichenified plaques in flexural } \\
\text { areas }\end{array}$ \\
$\begin{array}{llll}\text { Distribution } \\
\text { Scalp, face (without perioral and } \\
\text { periorbital involvement) trunk, extensor } \\
\text { surfaces }\end{array}$ & $\begin{array}{l}\text { Flexural surfaces, including antecubital and popliteal } \\
\text { fossa, wrist, and neck }\end{array}$ & $\begin{array}{l}\text { Hands, flexural surfaces, upper } \\
\text { trunk }\end{array}$ \\
\hline
\end{tabular}


Table 2 Associated features of atopic dermatitis. Modified from Ref. [1]

Pityriasis alba: Hypopigmented patches on face, upper trunk, upper extremities

Keratosis pilaris: Follicular hyperkeratosis of outer arms, lateral cheeks, buttocks, thighs

Dennie-Morgan fold (atopic pleat): Extra line on lower eyelid

Allergic shiners: Violaceous to gray color of infraorbital area

Hyperlinear palms: Increased and exaggerated skin markings on palms

Ichthyosis vulgaris: Scaling of extensor extremities, fish-scale appearance of extensor leg

Hertoghe sign: Loss of lateral eyebrows

White dermatographism: Blanching of skin after stroking

Circumoral pallor: Pallor of perioral area

Nummular dermatitis: Sharply circumscribed thick coin-shaped scaly plaques

Severity Index (EASI), the global assessment of the investigator (IGA), and the SASSAD (Six Area, Six Sign Atopic Dermatitis) [16].

The tools used for assessment of the intensity of itching are the Visual Analogue Scale (VAS), Numerical Scale, Verbal Scale, and Itching Severity Scale (ISS). However, there is no gold standard instrument for accurate assessment of the intensity and severity of pruritus and it is widely recommended that at least two should be used for reliable judgment [17].

\section{Complications}

In patients with DA, constant pruritus can lead to chronicity with the appearance of nummular eczema, lichenification and/or nodular prurigo. Bacterial and viral superinfections are a frequent complication due to altered skin barrier and itching. In addition, scratching may induce autoinoculation, particularly in the presence of molluscum contagiosum and impetigo [18].(Fig. 2).

The persistence of pruritus, sleep disturbance, and worsening of skin conditions have a negative impact on psychological development of the child and on the emotional status of both the child and his/her parents, affecting daily activities, social relationships, and quality of life. In some cases, care to the AD patient may generate a conflict between the parents and the non-affected children, who may feel neglected.

In some situations, targeted psychological intervention may be necessary. It is appropriate to suggest this in the presence of: (i) strongly involved parents (disproportion between the problem and its consequences), (ii) excessive influence of the disease on

Table 3 Atopic dermatitis and differential diagnosis. Modified from Ref. [1]

\begin{tabular}{|c|c|c|c|c|}
\hline Disease & Age & Morphology & Distribution & Symptoms \\
\hline$\overline{A D}$ & Childhood & $\begin{array}{l}\text { Erythematous eczematous weepy plaque } \\
\text { with fine dry scale }\end{array}$ & $\begin{array}{l}\text { Face, scalp, Extensor surfaces in infants, } \\
\text { flexural surfaces in children, trunk, nails }\end{array}$ & Severe pruritus \\
\hline $\begin{array}{l}\text { Seborrheic } \\
\text { dermatitis }\end{array}$ & Any age & $\begin{array}{l}\text { Salmon-pink fine papules coalescing into } \\
\text { poorly defined plaques with variable } \\
\text { greasy scaling. }\end{array}$ & $\begin{array}{l}\text { Face, scalp, Retroauricular folds, neck, } \\
\text { axillae, inguinal folds }\end{array}$ & $\begin{array}{l}\text { Absent to mild- } \\
\text { moderate pruritus }\end{array}$ \\
\hline Psoriasis & Any age & $\begin{array}{l}\text { Well-demarcated, pink plaques with } \\
\text { adherent silvery scale, confluent bright red } \\
\text { plaque with sharply defined borders and } \\
\text { relative lack of scale. }\end{array}$ & $\begin{array}{l}\text { Extensor surface of joints (elbows, knees) } \\
\text { and extremities, Retroauricular folds, } \\
\text { axillae, umbilicus, diaper area, inguinal } \\
\text { folds, genitalia, gluteal cleft, nails }\end{array}$ & $\begin{array}{l}\text { Mild-moderate } \\
\text { pruritus }\end{array}$ \\
\hline $\begin{array}{l}\text { Allergic contact } \\
\text { dermatitis }\end{array}$ & $\begin{array}{l}\text { Any age, } \\
\text { incidence } \\
\text { increases with } \\
\text { age }\end{array}$ & $\begin{array}{l}\text { Geometric erythematous eczematous } \\
\text { weepy plaques }\end{array}$ & Based on exposure & Severe pruritus \\
\hline Scabies & Any age & $\begin{array}{l}\text { Poorly defined erythematous papules, } \\
\text { nodules, burrows, pustules, and vesicles }\end{array}$ & $\begin{array}{l}\text { Wrists, interdigital spaces, axillae, } \\
\text { umbilicus, nipples, diaper area, }\end{array}$ & $\begin{array}{l}\text { Severe nocturnal } \\
\text { pruritus }\end{array}$ \\
\hline Mycosis fungoides & $\begin{array}{l}\text { Adulthood, } \\
\text { Hypopigmented } \\
\text { MF More } \\
\text { common in } \\
\text { children }\end{array}$ & $\begin{array}{l}\text { erythematous patches, papules, or plaques } \\
\text { with subtle scale; polycyclic or annular, } \\
\text { hypopigmented patches, often with fine } \\
\text { scaling }\end{array}$ & $\begin{array}{l}\text { Buttock, lower trunk, thighs, breasts, and } \\
\text { groin }\end{array}$ & Pruritus \\
\hline Dermatomyositis & $\begin{array}{l}\text { Childhood and } \\
\text { middle age }\end{array}$ & $\begin{array}{l}\text { Violaceous scaly papules, Periorbital } \\
\text { violaceous edema }\end{array}$ & Small joints of hands and elbows, face & Myositis \\
\hline $\begin{array}{l}\text { Immunodeficiency } \\
\text { and metabolic } \\
\text { disorders }\end{array}$ & Infancy & $\begin{array}{l}\text { Eczema or eczema-like eruption, } \\
\text { erythroderma }\end{array}$ & Spread, resistant to treatment & $\begin{array}{l}\text { Other cutaneous } \\
\text { and extracutaenous } \\
\text { manifestations } \\
\text { Blood testing and } \\
\text { genetic } \\
\text { investigations upon } \\
\text { diagnostic } \\
\text { hypothesis }\end{array}$ \\
\hline
\end{tabular}




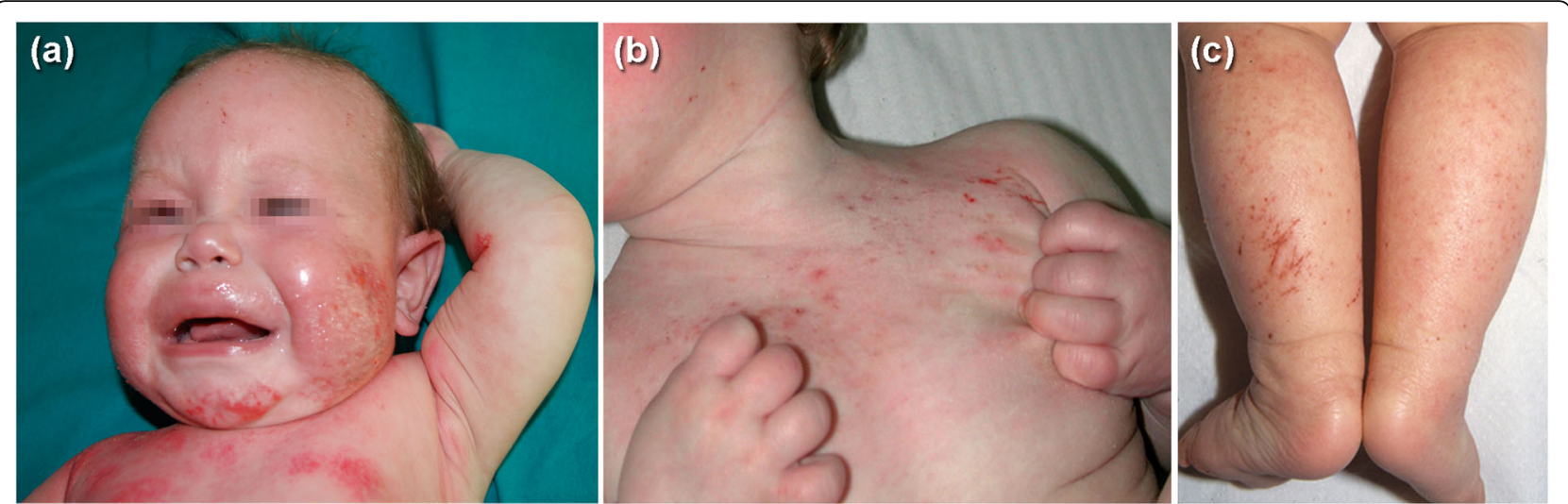

Fig. 1 a An infant aged 6 months affected by atopic dermatitis, exudative lesions on the cheeks and chest, and crying because of severe itching and pain. $\mathbf{b}$ Small babies even 2 and 3 months of age may scratch causing erosions. $\mathbf{c}$ scratching lesions on the legs

daily life and interpersonal relationships, (iii) parent/ child relationships characterized by mutual dependence, and (iv) psychological issues in a family member or in the functioning of the family nucleus.

\section{Therapeutic patient education}

The WHO defines therapeutic patient education (TPE) as a continuous process to train and guide the patient and his/her family to acquire the competencies needed to manage his/her chronic disease. TPE is mandatory for adequate management of $\mathrm{AD}$ and itching for several reasons:

- $\mathrm{AD}$ is a multidisciplinary disease with discordant opinions between specialists

- clinical features are polymorphic in the same day in the same patient

- early age of disease onset

- lack of specific treatment against pruritus

- sleep disturbance involving the family

- scarce compliance due to chronicity, time and costs for dressing

- esthetic damage

- psychosocial impact

TPE should be performed within the multidisciplinary approach required for AD. The specifically trained team should be minimally composed of a pediatrician, dermatologist, and dedicated nurse. In some cases, a psychologist is also required. All specialists should use the same language and provide the patient/family with a specific and tailored educational program. When required, other professional categories (e.g. allergologist) should be informed and take part in the TPE.

TPE can be performed within a group or individually and comprises:
- a theoretical aspect explaining the disease, its evolution and stressing its benign prognosis

- providing specific educational leaflets to the parents and children with adequate language

- a practical demonstration of dressing, patient massage, bandaging etc.

- strategies and tools for coping with itching and sleep disturbance (such as distraction techniques and their illustration)

- continuous evaluation of the patient and family perception

- psycho-diagnostic testing and psychotherapeutic intervention, when required.

A well-integrated and coordinated TPE program ensure adherence to treatment and better control of pruritus and sleep disturbance, thus reducing overall costs and improving QoL $[19,20]$.

\section{Medical treatment}

Antipruritic therapy is multidimensional aimed at minimizing symptoms and contributing factors such as dry skin, inflammation, and related scratch lesions. Therefore, several measures can be recommended [16, 18-20]. Treatment of $\mathrm{AD}$ improves itching. Evaluation of the efficacy of different therapies on itching is difficult due to multiple components influencing this symptom, including psychological attitude.

Immunotherapy to inhalants is indicated in addition to other topical and/or systemic treatment in order to improve itching and please add the reference [21].

\section{Topical therapy}

Topical therapy is mandatory to repair skin barrier and reduce itching and skin susceptibility to irritants. Hydration is always essential, even during remission. Several topical products are available, and the selected formulation should be cosmetically acceptable to the patient, and possibly 


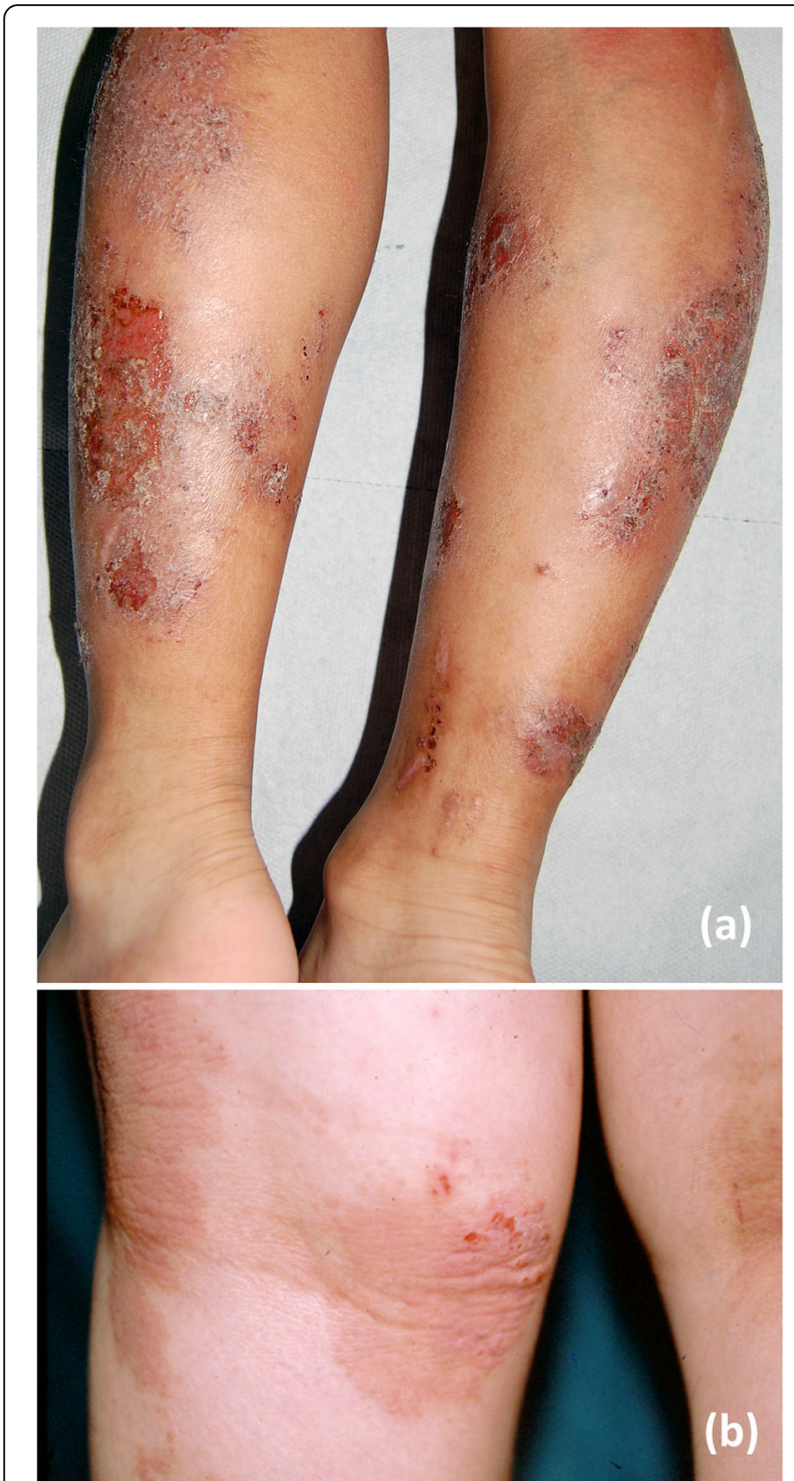

Fig. 2 a Erosions on the legs of a 9 years aged boy with $A D$, due to severe scratching, in this case there is a high risk of infection. $\mathbf{b}$ Chronic scratching in a girl with AD causing lichenification on the flexural regions of the left knee

inexpensive, in order to encourage good compliance. The specific choice of treatment depends on both individual and clinical features [16, 22-24].

Topical skin care For all topical skin care, it should be highlighted that specifically formulated products should be used, which are free of preservatives and perfumes [25].

- Cleansers. Oil, non-soap, or mild soap cleansers, without perfumes. Sodium hypochlorite (bleach) baths as antiseptic is an additional option [23, 24].
- Hydration. Emollients and moisturizers are a mainstay of pruritus management. As undressing could deteriorate itching, emollients should be applied on xerotic/lichenified skin not covered by clothes twice daily, and at least once daily to the entire surface of the skin, and more when undressing children for other reasons. They should be regularly applied, even during remission to prevent itching, flares, and complications [22, 23, 26, 27]. Emollients "plus" are non-medicated products containing active ingredients [28, 29].

\section{Anti-inflammatory therapy}

- Corticosteroids: topical corticosteroids (TCS) are still considered the mainstay of pharmacological treatment and first choice agents for inflammation and itching [18-20, 30, 31].

- Calcineurin inhibitors: tacrolimus ointment (0.03 and $0.1 \%$ ) and pimecrolimus cream (1\%) are immunomodulators used for moderate/severe and mild forms, respectively. It is important to take into account the age limit and possible contraindications (immunosuppression, exudative and infected lesions) [18-20, 32, 33].

\section{Antimicrobial therapy}

- Antimicrobials and antiseptics are necessary to treat infected lesions. Fusidic acid, retapamulin, and mupirocin are the most appropriate antibiotics [34, 35].

\section{Upcoming topical therapies}

- Topical phosphodiesterase 4 inhibitor, crisaborole, is an effective treatment of mild-to-moderate AD in patients from 2 years of age and is still experimental in Italy [36].

- Topical Janus kinase (JAK) inhibitors are being studied in clinical trials [37].

\section{Wet dressing, or wet-wrap therapy}

- The application of a topical medication followed by bandaging or wet dressing (a double layer of gauze or tubular dressings, the first layer moistened and the second layer dry) is indicated in exudative, infected or lichenified lesions, and protects against scratching and environmental irritants. It is also useful to promote absorption of topical products. Thus, it is important to take into account possible side effects, especially with concomitant corticosteroids [38, 39]. 


\section{Phototherapy}

UV therapy can be used in AD to relief pruritus. Narrowband UV-B and UV-A has been demonstrated to be the most preferable artificial radiation [40, 41].

\section{Systemic therapy}

Systemic therapies with confirmed effects against pruritus recommended by the guidelines are:

- Antihistamines. Short-term and intermittent courses of sedating (first-generation) antihistamines can be used in children if itch strongly affects quality of sleep [42-44].

- Systemic corticosteroids. Short courses of therapy may be indicated in special situations $[45,46]$.

- Systemic antimicrobial therapy. Antibiotics should be reserved exclusively for clear signs and symptoms of bacterial infection, and not simple bacterial colonization [45, 47].

- Oral immunomodulatory therapies. These are to be used for chronic itching recalcitrant to topical therapy [45, 48-51].

- Target therapy. Biologic agents against pathogenic cytokines and their receptors are a relatively new group of therapeutics [45]. Dupilumab (anti IL-4 and 13) is recommended as a disease-modifying drug for moderate-to-severe AD in Europe [52]. Treatments with ustekinumab (anti IL-12 and IL-23), tralokinumab (anti IL-13), or nemolizumab (anti-IL-31) are still experimental [53-56]. Oral drugs such as TSLP antagonists and JAK inhibitors are under development $[57,58]$. Their use should be restricted to very selected cases and used in specialized centers.

Therapeutic patient education follow-up and psychological support Despite the increasing prevalence of childhood AD, only a few studies have explored a specific educational approach in the last years. Recent national and international $\mathrm{AD}$ guidelines confirm that effective and standardized educational programs should be considered part of AD management and routine care. These treatment strategies are focused on patients and their families. Interventions must be delivered by a multidisciplinary team with an individual face-to-face or group education. The need for education and support will vary according to patient age, socio-cultural behavior, and severity of $\mathrm{AD}$. The educational approach should be preferably focused on families of children below 6 years of age because of the significant and high impact on disease and allow good management following disease onset. It is clear that the motivation to treat is high if the parents receive more (and correct) knowledge about the disease. Parents who play a key role in their children's treatment can considerably reduce the severity and impact of AD. This suggests that in addition to pharmacological treatment, providing educational support to parents is an important factor in achieving a positive long-term outcome. Less benefit for children more than 6 years with moderate or severe eczema has been reported because they become with time less motivated to treat themselves [59], and for this reason the educational program should start as soon as possible. The treatment of $\mathrm{AD}$ should ideally take into consideration both the patient's physical and emotional aspects and the impact of the disease in personal and family contexts. Attention to the emotional area allows: (i) promotion of a psychological elaboration that integrates information and emotions, facilitating memorization and consolidation of new information; (ii) creation of a relational context in a dedicated area for listening to the patient and his/her parents (knowing what he/she knows, how the patient lives with the illness, how much it influences them and their family); (iii) supporting the resources and skills of the patient and parents. An early start of the training process is important, before any feelings of ineffectiveness and mistrust and/or relationship difficulties and conflicts are established. For management of $\mathrm{AD}$ and pruritus, we think that education should be based on an approach that addresses the needs of the child and parents at a level they can comprehend. Educators are dermatologists, pediatricians, nurses and psychologists. The educators' role with the intervention group is to train, support, and motivate parents and children in self-management. One of the most important interventions in the management of $\mathrm{AD}$ is spending time listening to patients' concerns, explaining its causes, and showing how to apply topical therapies on the basis of clinical features of the lesions and patient age. The application of topical therapies is an essential part of the successful management of pruritus and atopic eczema. Longer consultations and forming a good caregiver-patient relationship are the strongest predictors of adherence to skin-care treatment. Performing this role requires well-trained educators [60].

Adjuvant therapies: distraction techniques Treatment of children with $\mathrm{AD}$ and pruritus and adequate management of the daytime and nighttime problems due to itching have a strong impact on the entire family context, making it necessary to focus on emotional and relational aspects. In order to facilitate the management of pediatric patients during application of dressings and to provide tools to deal with frequent itching, the use of specific distraction techniques is crucial. These nonpharmacological procedures with a psychological approach have been described in the literature [61-63], and are especially useful in pain management and during unpleasant procedures and or sensations. These are 
cognitive-behavioral techniques, aimed at shifting attention from pruritus and medication towards activities that intensely absorb the patient: the techniques imply active sensory perception, and not just a passive strategy, that can be entertaining the child. The techniques are based on two principles: (i) children have mental boundaries between fantasy and reality that are more fluid and permeable than in adults; (ii) and it is difficult, if not impossible, for a human to focus on more than one or two sensory stimuli at once. A detailed description of distraction techniques by age group along with specific examples is provided as Additional file 1.

The choice of distraction techniques (involvement, breathing, relaxation, hypnotic procedures such as visualization and desensitization) depends on several factors: age, personality, individual likes and dislikes, motivation, and emotions of reference figures. In addition, even the time of day is important since, for example, at night a massage would be favored over watching a cartoon. The application of these tools allows defusing the phenomenon of anticipatory anxiety and increased compliance to treatment. These techniques are useful not only for children, who are the main recipients, but also for parents and siblings. It is therefore important to educate the entire family on their use, and to adapt them in specific situations. Distraction techniques are also helpful to parents to feel more relaxed, they improve the interaction with their child, transmitting greater security and managing the disease with less anxiety. The utility of learning techniques has also been documented in the parents of very young children [59-62].

\section{Conclusions}

The focus of the present summary document was to increase awareness of pruritus in pediatric patients with AD. In addition, the authors tried to provide a useful tool for all specialists who managed patient with this disease and pruritus. Emollients, as reported by the literature are considered the backbone in restoring the skin barrier, reducing itching and relapses. The psychological support should be contemplated as one of the several therapeutic options available or on trial. Finally, it is emphasized that a multidisciplinary approach is always necessary to guarantee an adequate management of patients with AD. Moreover, educational interventions can greatly improve reducing symptoms, improving the adherence to treatment and the overall quality of life for both young sufferers and their parents.

\section{Supplementary information}

Supplementary information accompanies this paper at https://doi.org/10. 1186/s13052-020-0777-9.

Additional file 1:. Descrition of distraction techniques by age group.

\section{Abbreviations}

AD: Atopic Dermatitis; EASI: Eczema Area and the Severity Index;

IGA: Investigator Global Assessment; ILCs: Innate Lymphoid Cells; ISS: Itching Severity Scale; QoL: Overall Quality of Life; SASSAD: Six Area Six Sign Atopic Dermatitis; SCORAD: SCORing Atopic Dermatitis; TCS: Topical Corticosteroids; TEWL: Transepidermal Water Loss; TPE: Therapeutic Patient Education;

TSLP: Thymic Stromal Lymphopoietin; VAS: Visual Analogue Scale

\section{Acknowledgements}

The authors would like to thank the children affected by AD for their collaboration in the path of therapeutic education and in the fruitful use of distraction techniques. We also thank Mr. Gabriele Bacile for his help with figures. Editorial support was provided by Edra spa, and unconditionally funded by Pierre Fabre.

\section{Authors' contributions}

All authors participated in the and drafting and reviewing the manuscript and read and approved the final manuscript.

Funding

Not applicable.

Availability of data and materials

Data sharing not applicable to this article as no datasets were generated or analyzed during the current study.

Ethics approval and consent to participate

Not applicable.

Consent for publication

Not applicable.

\section{Competing interests}

The authors declare that they have no competing of interest.

\section{Author details}

${ }^{1}$ Dermatology Unit, Bambino Gesù Children's Hospital, IRCCS, Piazza di Sant'Onofrio, 4, 00165 Rome, Italy. PPrimary Care Pediatrics, ASL Caserta, Caserta, Italy. ${ }^{3}$ Unit of Clinical Psychology, Ospedale Pediatrico Bambino Gesù (IRCCS), Rome, Italy. ${ }^{4}$ Bambino Gesù Children's Hospital, IRCCS, Rome, Italy. ${ }^{5}$ Primary Care Pediatrics, ASL Salerno, Vietri sul Mare, Italy. ${ }^{6}$ Unit of Pediatrics, Fatebenefratelli Hospital, Benevento, Italy.

Received: 18 April 2019 Accepted: 21 January 2020

Published online: 30 January 2020

\section{References}

1. Barrett M, Luu M. Differential diagnosis of atopic dermatitis. Immunol Allergy Clin N Am. 2017:37(1):11-34.

2. Weidinger S, Novak N. Atopic dermatitis. Lancet. 2016 Mar 12;387(10023):1109-22.

3. Kido-Nakahara M, Furue M, Ulzii D, Nakahara T. Itch in atopic dermatitis. Immunol Allergy Clin N Am. 2017;37(1):113-22.

4. Furue M, Chiba T, Tsuji G, Ulzii D, Kido-Nakahara M, Nakahara T, et al. Atopic dermatitis: immune deviation, barrier dysfunction, IgE autoreactivity and new therapies. Allergol Int. 2017;66(3):398-403.

5. Rerknimitr P, Otsuka A, Nakashima C, Kabashima K. The etiopathogenesis of atopic dermatitis: barrier disruption, immunological derangement, and pruritus. Inflamm Regen [Internet]. 2017;5:37 Available from: https://www. ncbi.n/m.nih.gov/pmc/articles/PMC5725646/, [cited 2018 Oct 31].

6. Murota $\mathrm{H}$, Katayama I. Exacerbating factors of itch in atopic dermatitis. Allergol Int. 2017;66(1):8-13.

7. Mollanazar NK, Smith PK, Yosipovitch G. Mediators of chronic pruritus in atopic dermatitis: getting the itch out? Clin Rev Allergy Immunol. 2016;51(3):263-92.

8. Leyva-Castillo JM, Hener P, Michea P, Karasuyama H, Chan S, Soumelis V, et al. Skin thymic stromal lymphopoietin initiates Th2 responses through an orchestrated immune cascade. Nat Commun. 2013;4:2847.

9. Mu D, Deng J, Liu K-F, Wu Z-Y, Shi Y-F, Guo W-M, et al. A central neural circuit for itch sensation. Science. 2017;357(6352):695-9.

10. Tominaga $M$, Takamori $K$. Itch and nerve fibers with special reference to atopic dermatitis: therapeutic implications. J Dermatol. 2014;41(3):205-12. 
11. Teresiak-Mikołajczak E, Czarnecka-Operacz M, Jenerowicz D, Silny W. Neurogenic markers of the inflammatory process in atopic dermatitis: relation to the severity and pruritus. Postepy Dermatol Alergol. 2013;30(5):286-92.

12. Trier AM, Kim BS. Cytokine modulation of atopic itch. Curr Opin Immunol. 2018;54:7-12.

13. Lu J, Wu K, Zeng Q, Xiang Y, Gao L, Huang J. Serum interleukin-31 level and pruritus in atopic dermatitis: a meta-analysis. Zhong Nan Da Xue Xue Bao Yi Xue Ban. 2018;43(2):124-30.

14. Metz M, Wahn U, Gieler U, Stock P, Schmitt J, Blume-Peytavi U. Chronic pruritus associated with dermatologic disease in infancy and childhood: update from an interdisciplinary group of dermatologists and pediatricians. Pediatr Allergy Immunol. 2013;24(6):527-39.

15. Boguniewicz $M$, Alexis AF, Beck LA, Block J, Eichenfield LF, Fonacier $L$, et al. Expert perspectives on Management of Moderate-to-Severe Atopic Dermatitis: a multidisciplinary consensus addressing current and emerging therapies. J Allergy Clin Immunol Pract. 2017;5(6):1519-31.

16. Eichenfield LF, Tom WL, Berger TG, Krol A, Paller AS, Schwarzenberger K, et al. Guidelines of care for the management of atopic dermatitis: section 2 Management and treatment of atopic dermatitis with topical therapies. J Am Acad Dermatol. 2014;71(1):116-32.

17. Bruscky DMV, Melo ACCDB, ESC S. Cross-cultural adaptation and validation of the itching severity scale in children and adolescents with atopic dermatitis. Rev Paul Pediatr. 2017;35(3):244-51.

18. Wollenberg A, Barbarot S, Bieber T, Christen-Zaech S, Deleuran M, FinkWagner A, et al. Consensus-based European guidelines for treatment of atopic eczema (atopic dermatitis) in adults and children: part I. J Eur Acad Dermatol Venereol. 2018;32(5):657-82

19. Wollenberg A, Barbarot S, Bieber T, Christen-Zaech S, Deleuran M, FinkWagner A, et al. Consensus-based European guidelines for treatment of atopic eczema (atopic dermatitis) in adults and children: part II. J Eur Acad Dermatol Venereol. 2018;32(6):850-78

20. Galli E, Neri I, Ricci G, Baldo E, Barone M, Belloni Fortina A, et al. Consensus conference on clinical management of pediatric atopic dermatitis. Ital J Pediatr. 2016;42:26.

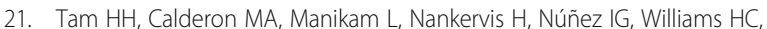
et al. Specific allergen immunotherapy for the treatment of atopic eczema: a Cochrane systematic review. Allergy. 2016;71(9):1345-56.

22. Blume-Peytavi U, Metz M. Atopic dermatitis in children: management of pruritus. J Eur Acad Dermatol Venereol. 2012;26(Suppl 6):2-8.

23. Elmariah SB, Lerner EA. Topical therapies for pruritus. Semin Cutan Med Surg. 2011;30(2):118-26.

24. Hon KL, Tsang YCK, Lee WWY, Pong NH, Ha G, Lee ST, et al. Efficacy of sodium hypochlorite (bleach) baths to reduce Staphylococcus aureus colonization in childhood onset moderate-to-severe eczema: a randomized, placebo-controlled cross-over trial. J Dermatolog Treat. 2016;27(2):156-62.

25. Kwangmi K. Influences of environmental chemicals on atopic dermatitis. Toxicol Res. 2015;31(2):89-96.

26. Simpson EL, Chalmers JR, Hanifin JM, Thomas KS, Cork MJ, McLean WHI, et al. Emollient enhancement of the skin barrier from birth offers effective atopic dermatitis prevention. J Allergy Clin Immunol. 2014;134(4):818-23.

27. Boralevi F, Saint Aroman M, Delarue A, Raudsepp H, Kaszuba A, Bylaite M, et al. Long-term emollient therapy improves xerosis in children with atopic dermatitis. J Eur Acad Dermatol Venereol. 2014;28(11):1456-62.

28. Åkerström U, Reitamo S, Langeland T, Berg M, Rustad L, Korhonen L, et al. Comparison of moisturizing creams for the prevention of atopic dermatitis relapse: a randomized double blind controlled multicentre dinical trial. Acta Derm Venereol. 2015:95(5):587-92.

29. Fostini AC, Georgescu V, Decoster CJ, Girolomoni G. A cream based on Aquaphilus dolomiae extracts alleviates non-histaminergic pruritus in humans. Eur J Dermatol. 2017:27(3):317-8.

30. Ference JD, Last AR. Choosing topical corticosteroids. AFP. 2009:79(2):135-40.

31. Chong M, Fonacier L. Treatment of eczema: corticosteroids and beyond. Clin Rev Allergy Immunol. 2016;51(3):249-62.

32. Carr WW. Topical calcineurin inhibitors for atopic dermatitis: review and treatment recommendations. Paediatr Drugs. 2013;15(4):303-10

33. Wollenberg A, Bieber T. Proactive therapy of atopic dermatitis--an emerging concept. Allergy. 2009 Feb;64(2):276-8.

34. Tang C-S, Wang C-C, Huang C-F, Chen S-J, Tseng M-H, Lo W-T. Antimicrobial susceptibility of Staphylococcus aureus in children with atopic dermatitis. Pediatr Int. 2011;53(3):363-7.

35. Bonamonte D, Belloni Fortina A, Neri L, Patrizi A. Fusidic acid in skin infections and infected atopic eczema. G Ital Dermatol Venereol. 2014; 149(4):453-9.
36. Paller AS, Tom WL, Lebwohl MG, Blumenthal RL, Boguniewicz M, Call RS, et al. Efficacy and safety of crisaborole ointment, a novel, nonsteroidal phosphodiesterase 4 (PDE4) inhibitor for the topical treatment of atopic dermatitis (AD) in children and adults. J Am Acad Dermatol. 2016;75(3):494-503.e6.

37. Bissonnette R, Papp KA, Poulin Y, Gooderham M, Raman M, Mallbris L, et al. Topical tofacitinib for atopic dermatitis: a phase lla randomized trial. $\mathrm{Br}$ J Dermatol. 2016;175(5):902-11.

38. Andersen RM, Thyssen JP, Maibach $\mathrm{HI}$. The role of wet wrap therapy in skin disorders - a literature review. Acta Derm Venereol. 2015;95(8):933-9.

39. Janmohamed SR, Oranje AP, Devillers AC, Rizopoulos D, van Praag MCG, Van Gysel D, et al. The proactive wet-wrap method with diluted corticosteroids versus emollients in children with atopic dermatitis: a prospective, randomized, double-blind, placebo-controlled trial. J Am Acad Dermatol. 2014;70(6):1076-82.

40. Gambichler T, Othlinghaus N, Tomi NS, Holland-Letz T, Boms S, Skrygan M, et al. Medium-dose ultraviolet (UV) A1 vs. narrowband UVB phototherapy in atopic eczema: a randomized crossover study. Br J Dermatol. 2009:160(3):652-8.

41. Garritsen FM, Brouwer MWD, Limpens J, Spuls PI. Photo(chemo)therapy in the management of atopic dermatitis: an updated systematic review with implications for practice and research. Br J Dermatol. 2014;170(3):501-13.

42. Church MK, Maurer M. H1 -antihistamines and itch in atopic dermatitis. Exp Dermatol. 2015;24(5):332-3.

43. van Zuuren EJ, Apfelbacher CJ, Fedorowicz Z, Jupiter A, Matterne U, Weisshaar E. No high level evidence to support the use of oral $\mathrm{H1}$ antihistamines as monotherapy for eczema: a summary of a Cochrane systematic review. Syst Rev. 2014;3:25.

44. Thurmond RL. The histamine $\mathrm{H} 4$ receptor: from orphan to the clinic. Front Pharmacol. 2015:6:65.

45. Slater NA, Morrell DS. Systemic therapy of childhood atopic dermatitis. Clin Dermatol. 2015 Jun;33(3):289-99.

46. Liu D, Ahmet A, Ward L, Krishnamoorthy P, Mandelcorn ED, Leigh R, et al. A practical guide to the monitoring and management of the complications of systemic corticosteroid therapy. Allergy Asthma Clin Immunol. 2013;9(1):30.

47. Travers JB, Kozman A, Yao Y, Ming W, Yao W, Turner MJ, et al. Treatment outcomes of secondarily impetiginized pediatric atopic dermatitis lesions and the role of oral antibiotics. Pediatr Dermatol. 2012;29(3):289-96.

48. Notaro ER, Sidbury R. Systemic agents for severe atopic dermatitis in children. Paediatr Drugs. 2015:17(6):449-57.

49. Schmitt J, Schmitt N, Meurer M. Cyclosporin in the treatment of patients with atopic eczema - a systematic review and meta-analysis. J Eur Acad Dermatol Venereol. 2007;21(5):606-19.

50. Tsakok T, Flohr C. Methotrexate vs. ciclosporin in the treatment of severe atopic dermatitis in children: a critical appraisal. Br J Dermatol. 2014;170(3): 496-8 discussion 498-499.

51. Waxweiler WT, Agans R, Morrell DS. Systemic treatment of pediatric atopic dermatitis with azathioprine and mycophenolate mofetil. Pediatr Dermatol. 2011:28(6):689-94.

52. Hamilton JD, Suárez-Fariñas M, Dhingra N, Cardinale I, Li X, Kostic A, et al. Dupilumab improves the molecular signature in skin of patients with moderate-tosevere atopic dermatitis. J Allergy Clin Immunol. 2014;134(6):1293-300.

53. Fernández-Antón Martínez MC, Alfageme Roldán F, Ciudad Blanco C, Suárez FR Ustekinumab in the treatment of severe atopic dermatitis: a preliminary report of our experience with 4 patients. Actas Dermosifiliogr. 2014;105(3):312-3.

54. Wollenberg A, Howell MD, Guttman-Yassky E, Silverberg II, Kell C, Ranade K, et al. Treatment of atopic dermatitis with tralokinumab, an anti-IL-13 mAb. J Allergy Clin Immunol. 2018;12.

55. Kabashima K, Furue M, Hanifin J, Pulka G, Mlynarczyk I, Wollenberg A, et al. 005 humanized anti-interleukin-31 receptor a antibody nemolizumab (CIM331) suppresses pruritus and improves eczema in patients with moderate-to-severe atopic dermatitis. J Invest Dermatol. 2016;136(9):S161.

56. Volf EM, Au S-C, Dumont N, Scheinman P, Gottlieb AB. A phase 2, openlabel, investigator-initiated study to evaluate the safety and efficacy of apremilast in subjects with recalcitrant allergic contact or atopic dermatitis. J Drugs Dermatol. 2012;11(3):341-6.

57. Samadi A, Ahmad Nasrollahi S, Hashemi A, Nassiri Kashani M, Firooz A. Janus kinase (JAK) inhibitors for the treatment of skin and hair disorders: a review of literature. J Dermatolog Treat. 2017;28(6):476-83.

58. Arm JP, Bottoli I, Skerjanec A, Floch D, Groenewegen A, Maahs S, et al. Pharmacokinetics, pharmacodynamics and safety of QGE031 (ligelizumab), a novel high-affinity anti-lgE antibody, in atopic subjects. Clin Exp Allergy. 2014:44(11):1371-85 
59. Liang Y, Tian J, Shen CP, Xu F, Wang H, Li P, et al. Therapeutic patient education in children with moderate to severe atopic dermatitis: a multicenter randomized controlled trial in China. Pediatr Dermatol. 2018;35(1):70-5.

60. Barbarot S, Bernier C, Deleuran M, De Raeve L, Eichenfield L, El Hachem M, et al. Therapeutic patient education in children with atopic dermatitis: position paper on objectives and recommendations. Pediatr Dermatol. 2013; 30(2):199-206

61. Leibovici V, Magora F, Cohen S, Ingber A. Effects of virtual reality immersion and audiovisual distraction techniques for patients with pruritus. Pain Res Manag. 2009;14(4):283-6.

62. Grillo $\mathrm{M}$, Long $\mathrm{R}$, Long $\mathrm{D}$. Habit reversal training for the itch-scratch cycle associated with pruritic skin conditions. Dermatol Nurs. 2007;19(3):243-8.

63. Han L, Dong X. Itch mechanisms and circuits. Annu Rev Biophys. 2014:43:331-55.

\section{Publisher's Note}

Springer Nature remains neutral with regard to jurisdictional claims in published maps and institutional affiliations.

Ready to submit your research? Choose BMC and benefit from:

- fast, convenient online submission

- thorough peer review by experienced researchers in your field

- rapid publication on acceptance

- support for research data, including large and complex data types

- gold Open Access which fosters wider collaboration and increased citations

- maximum visibility for your research: over $100 \mathrm{M}$ website views per year

At BMC, research is always in progress.

Learn more biomedcentral.com/submissions 